\title{
Successful treatment of hepatoportal arteriovenous fistula by transcatheter embolization with steel coils
}

\author{
TARALYN D PICTON MD FRCPC, LINDSAY MACHAN MD FRCPC, JENNIFER DAVIS MD FRCPC, \\ HUGH J FREEMAN MD FRCPC, URS P STEINBRECHER MD FRCPC
}

TD Picton, L Machan, J Davis, HJ Freeman, UP Steinbrecher. Successful treatment of hepatoportal arteriovenous fistula by transcatheter embolization with steel coils. Can J Gastroenterol 1994;8(5):313-316. Portal hypertension is most commonly caused by increased intrahepatic resistance as a result of cirrhosis, but can also occur as a result of abnormally high portal bloodflow. This article describes a patient with a history of remote liver trauma in whom portal hypertension and variceal bleeding were shown to be due to an arteriovenous fistula between the hepatic artery and portal vein. Transcatheter embolization with Gianturco coils resulted in obliteration of the fistula and normalization of portal pressures.

Key Words: Arteriovenous fistula, Hepatoportal fistula, Portal hypertension, Transcatheter embolization

\section{Traitement réussi d'une fistule artérioveineuse hépatoportale} par embolisation à l'aide d'endoprothèses installées par

\section{cathétérisme}

RÉSUMÉ : L'hypertension portale est le plus souvent causée par une résistance intra-hépatique accrue des suites d'une cirrhose, mais elle peut également survenir à cause d'un débit sanguin porte anormalement élevé. Cet article décrit un patient présentant des antécédents de traumatisme hépatique ancien, chez qui une hypertension portale et des hémorragies variqueuses se sont révélées attribuables à une fistule artérioveineuse entre l'artère hépatique et la veine porte. Une embolisation par cathéter à l'aide d'endoprothèses de Gianturco a provoqué une oblitération de la fistule et a normalisé les pressions portales.

Departments of Medicine (Gastroenterology), Radiology and Pathology, University of British Columbia, Vancouver, British Columbia

Correspondence and reprints: Dr Urs P Steinbrecher, Department of Medicine, Vancouver Hospital and Health Sciences Centre, UBC Site, 2211 Wesbrook Mall, Vancouver, British

Columbia V6T 1W5. Telephone (604) 822-7727, Fax (604) 822-7897

Received for publication July 29, 1993. Accepted January 20, 1994
P ORTAL HYPERTENSION AND ITS most dramatic complication, variceal hemorrhage, are frequently encountered in clinical gastroenterology. While most cases of portal hypertension are the result of increased intrahepatic resistance associated with cirrhosis, portal hypertension can also be caused by abnormally high portal bloodflow. The present report describes a patient with hepatitis $\mathrm{C}$ in whom portal hypertension and variceal bleeding were shown to be due to an arteriovenous fistula between the right hepatic artery and portal vein resulting from remote liver trauma. The patient was treated by transcatheter embolization of the right hepatic artery, which obliterated the fistula and restored portal pressures to normal. This case illustrates the importance of recognizing noncirrhotic causes of portal hypertension so that specific therapeutic intervention may be possible.

\section{CASE PRESENTATION}

A 34-year-old man presented with a three-week history of jaundice and pruritus accompanied by aching right upper quadrant discomfort. He also noted fatigue, nausea and anorexia that 

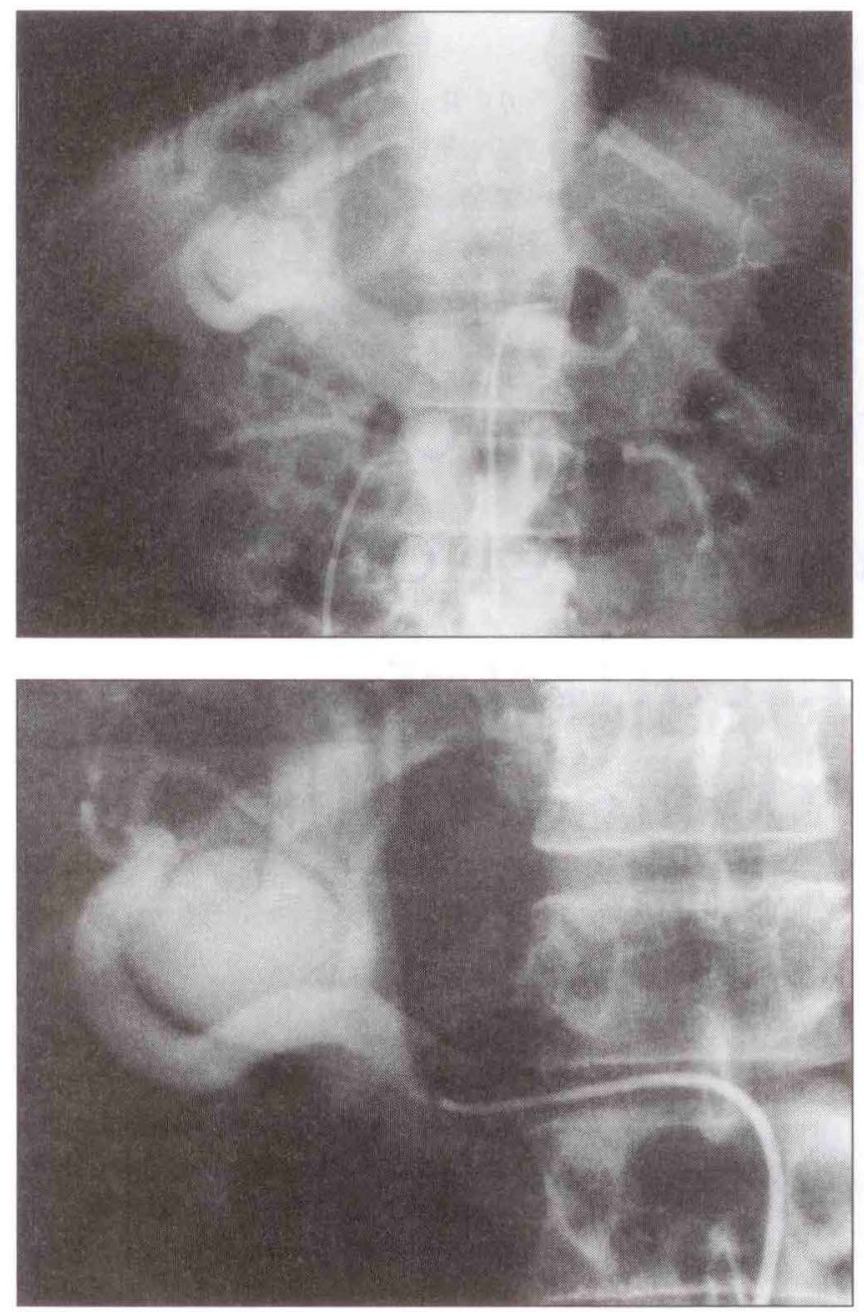

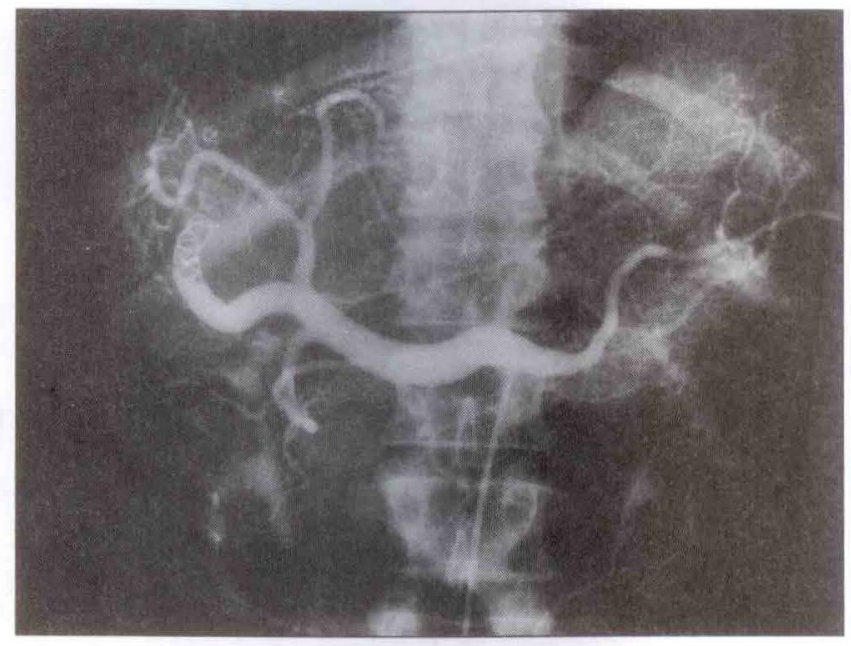

Figure 3) Celiac arteriogram after embolization demonstrating complete occlusion of the right hepatic artery by Gianturco coils and nonfilling of the fistula. Delayed films showed normal portal vein opacification

Figure 1) Top left Celiac axis arteriogram showing filling of the portal vein during early arterial phase. Contrast is diluted because of markedly increased flow through the hepatic artery

Figure 2) Left Selective injection of proper hepatic artery. The right hepatic artery is dilated and there is bulbous dilation of the right portal vein immediately beyond the fistula had resulted in weight loss of $6 \mathrm{~kg}$. There was no history of intravenous drug abuse or alcohol excess, and he took no medications other than occasional over-the-counter analgesics. He was heterosexual and monogamous. Seventeen years previously he had sustained a crush injury to the abdomen in a motorcycle accident. Emergency laparotomy at that time revealed massive hemoperitoneum with shattered right lobe of liver and a ruptured spleen. Right hepatectomy, cholecystectomy and splenectomy were performed. At least 10 units of blood and plasma were administered. Two weeks postoperatively the patient had required surgical drainage of a right subphrenic abscess, but otherwise his recovery was uneventful. He remained well subsequently with no signs or symptoms of liver disease until his present illness.

Physical examination revealed icterus. Mentation was normal. There were no peripheral stigmata of chronic liver disease. Abdominal examination revealed an enlarged, firm, moderately tender left lobe of liver. There was no detectable ascites.

Hemoglobin was $152 \mathrm{~g} / \mathrm{L}$, white blood cell count $8.1 \times 10^{9} / \mathrm{L}$, platelets $492 \times 10^{9} / \mathrm{L}$, prothrombin time $11.8 \mathrm{~s}$, and electrolytes, blood urea nitrogen (BUN), creatinine, albumin and total protein were all normal. Aspartate aminotransferase (AST) was $194 \mathrm{IU} / \mathrm{L}$ (normal 10 to 47), alkaline phosphatase (AP) $139 \mathrm{IU} / \mathrm{L}$ (normal 11 to 189 ), total bilirubin $60 \mu \mathrm{mol} / \mathrm{L}$ (normal 9 to 26) and direct bilirubin $52 \mu \mathrm{mol} / \mathrm{L}$ (normal 0 to 9 ). Hepatitis B surface antigen, anti-hepatitis B core antigen and antihepatitis $\mathrm{A}$ virus immunoglobulin $\mathrm{M}$ were negative. Abdominal sonography revealed distortion of the anatomy from the previous hepatic lobectomy. There was no dilation of intrahepatic bile ducts, and the gallbladder was absent. The common bile duct was not well seen.
Ten days later, total bilirubin was 170 $\mu \mathrm{mol} / \mathrm{L}$, AST $144 \mathrm{IU} / \mathrm{L}$, AP $201 \mathrm{IU} / \mathrm{L}$ and gamma-glutamyltransferase $315 \mathrm{IU} / \mathrm{L}$ (normal 0 to 65 ). Over the next month, the patient's symptoms resolved and the bilirubin returned to normal.

Two months after his initial presentation, he developed hematemesis, and was admitted to a regional hospital. Esophagogastroscopy revealed four large esophageal varices, a large amount of blood clot in the gastric fundus and no abnormalities in the gastric antrum or duodenum. Sclerotherapy with a total of $20 \mathrm{~mL}$ ethanolamine oleate was performed. An additional $16 \mathrm{~mL}$ ethanolamine oleate were injected at a follow-up procedure one week later. Varices were still present at a third session one months later and a further $18 \mathrm{~mL}$ ethanolamine oleate were injected. Ten days after the third sclerotherapy the patient developed recurrent hematemesis. The patient presented to a community hospital and 

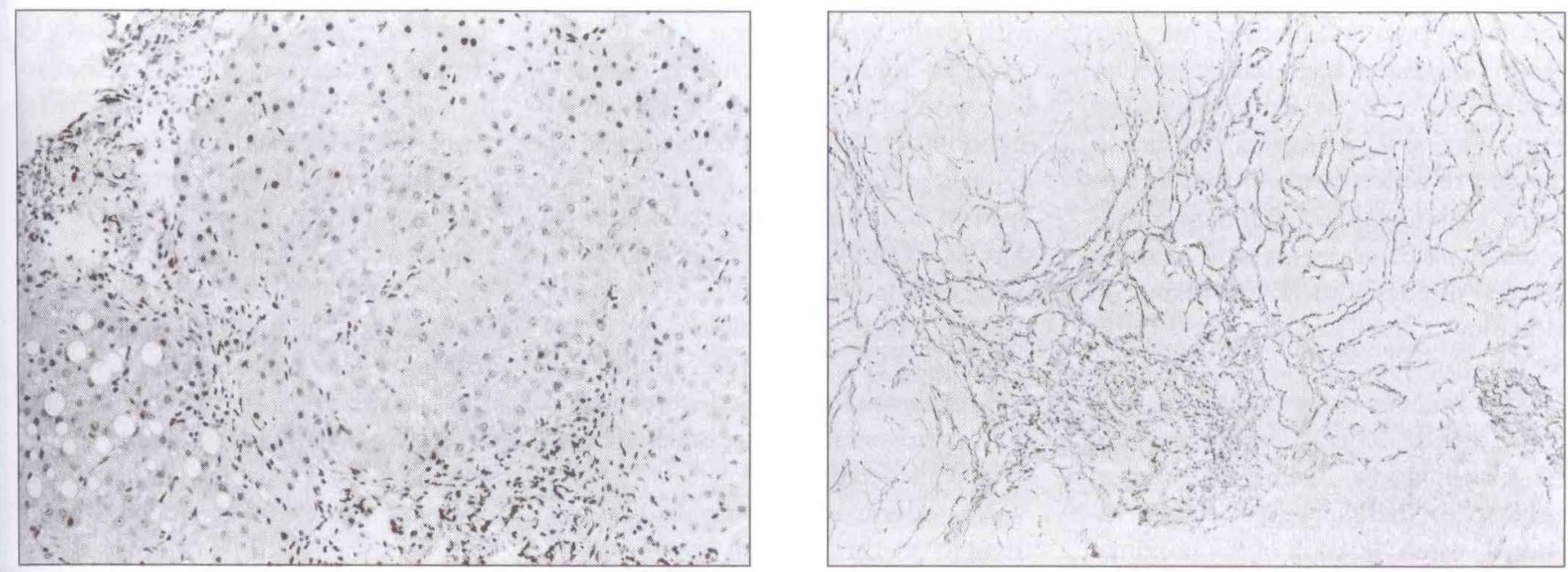

Figure 4) Sections of a needle liver biopsy showing focal intralobular hepatocellular necrosis with aggregates of histiocytes and lymphocytes within lobules. The limiting plate of portal triads is mildly irregular, but there is no definite piecemeal necrosis. The reticulin stain shows mild fibrosis and a suggestion of nodular regeneration. Left Hematoxylin and eosin stain X124; Right Reticulin stain X124

underwent an esophagogastroscopy, which revealed esophageal varices and esophageal ulceration.

Because of ongoing bleeding, the patient was transferred to University Hospital in Vancouver, British Columbia. On physical examination, note was made of a soft, localized bruit in the right upper quadrant. Esophagogastroscopy revealed two moderate esophageal varices and a linear esophageal ulcer likely related to previous sclerotherapy. There was a moderate amount of blood in the gastric fundus, but no active bleeding. The varices were injected with $4 \mathrm{~mL}$ sodium tetradecyl sulphate. There was no subsequent bleeding and follow-up endoscopy revealed complete obliteration of varices. Bilirubin, albumin and prothrombin time were normal but AST remained elevated at $84 \mathrm{IU} / \mathrm{L}$. Antinuclear antibodies, antimitochondrial antibodies, ceruloplasmin and alpha-1 antitrypsin were normal. Antibody to hepatitis $\mathrm{C}$ was positive. Because of the history of liver resection for trauma, additional investigations were carried out to define the cause of the portal hypertension. Abdominal sonography with colour duplex Doppler revealed pulsatile high velocity flow and turbulence within a dilated segment of the portal vein. Hepatic vein catheterization revealed a hepatic vein wedge pressure $33 \mathrm{mmHg}$ above inferior vena cava pressure. Celiac and selective he- patic arteriograms showed dilation of the proper and right hepatic arteries, with truncation of the right hepatic artery about $8 \mathrm{~cm}$ distal to its origin. At the point of truncation there was a fistula to a dilated stump of right portal vein (Figures 1,2). The left hepatic artery was unremarkable. The right hepatic artery was embolized with two 10 $\mathrm{mm}$ diameter stainless steel coils, which resulted in complete occlusion of this vessel (Figure 3). An ultrasoundguided needle biopsy of the liver was performed. This showed evidence of focal intralobular hepatocellular necrosis with aggregates of histocytes and lymphocytes within lobules. Occasional Councilman bodies were present. The limiting plate of portal triads was mildly irregular, but no clear evidence of piecemeal necrosis was evident (Figure 4). These changes were consistent with hepatitis C. There was mild fibrosis, which could have been the result of chronic hepatitis C. Nodular regeneration was evident, but seemed out of proportion to the fibrosis and so was thought to be a consequence of the hepatic resection rather than a manifestation of cirrhosis. Repeat hepatic vein catheterization one month after embolization demonstrated that the hepatic wedge pressure had restored to near-normal $(9 \mathrm{mmHg})$. Esophagogastroscopy revealed no residual esophageal varices. The patient has remained clinically well (now more than two years postembolization), although his AST levels remain mildly elevated. It has not been established if the episode of jaundice that led to his initial presentation represented a reactivation of chronic hepatitis $\mathrm{C}$ acquired as a result of blood transfusions during resuscitation from trauma 17 years earlier, or a more recent exposure.

\section{DISCUSSION}

Hepatoportal arteriovenous communications are a rare cause of portal hypertension (1), but need to be recognized as they carry specific therapeutic implications. Such communications can be congenital (2) but are more often acquired as the result of trauma, ruptured arterial aneurysm or surgery $(3,4)$. They are seen occasionally in patients with hepatocellular carcinoma (5). Iatrogenic hepatoportal fistulas can be demonstrated in $5 \%$ of patients following needle liver biopsy when angiography is done within one week of biopsy, but in most cases these are peripheral, do not cause portal hypertension and generally close spontaneously $(6,7)$.

Post-traumatic hepatoportal fistulas occasionally present acutely, with ascites and abdominal pain within weeks of the injury, but in most cases they remain clinically silent for many years $(3,8,9)$. The typical presenting manifestation is variceal hemorrhage, although features such as ascites, 
abdominal pain and diarrhea may also occur. Congestive heart failure was present in $16 \%$ of the patients reviewed by Van Way and colleagues (3) but is thought to be less frequent than in systemic arteriovenous communications because with hepatoportal fistulas there is often significant resistance to bloodflow, contributed by portal venulae and sinusoids (9).

Treatment of symptomatic hepatoportal fistulas depends on etiology and vascular anatomy. Traditional surgical approaches include repair of the involved vessels, ligation of the proximal portion of the feeding artery or resection of the involved portion of liver (3). Successful transcatheter embolization of hepatoportal fistulas with absorbable gelatin sponges (Gelfoam, Upjohn) has been described, but embolization with this material seems to be associated

\section{REFERENCES}

1. McDermott WV, Bothe A Jr, Clouse MF, Bern MM. Noncirrhotic portal hypertension in adults. Am J Surg 1981;141:514-8.

2. Helikson MA, Shapiro DL, Seashore JH. Hepatoportal arteriovenous fistula and portal hypertension in an infant. Pediatrics 1977;60:920-4.

3. Van Way CW III, Riddell JMCH, Foster JH. Arteriovenous fistula in the portal circulation. Surgery 1971;70:876-90.

4. Vujic I, Meredith HC, Ameriks JA. Embolization for hepatoportal arteriovenous fistula. Am Surg 1980;46:366-70.

5. Morse SS, Sniderman KW, Galloway S, Rapoport S, Ross GR, Glickman MG. Hepatoma, arterioportal shunting, and hyperkinetic portal with early recanalization $(4,9,10)$ or outright failure of occlusion particularly with large fistulas $(2,8)$. Results of embolization with steel coils appear to be more encouraging $(8,11,12)$, but even with this technique there is a report of recanalization and recurrent variceal hemorrhage (9). In circumstances where the fistula cannot be controlled and there are significant symptoms related to portal hypertension, portosystemic shunting may need to be considered (9).

Mesenteric arterioportal fistulas are thought to cause portal hypertension by increasing portal bloodflow in the face of relatively fixed intrahepatic resistance. This characteristically leads to 'prehepatic' portal hypertension with normal or minimally abnormal sinusoidal pressure. In the present case, hepatic vein wedge pressures were

hypertension: therapeutic embolization. Radiology 1985; 155:77-82.

6. Okuda K, Musha H, Najkajima Y. Frequency of intrahepatic arteriovenous fistula as a sequel to percutaneous needle puncture of the liver. Gastroenterology 1978;74:1204-7.

7. Hashimoto E, Ludwig J, MacCarty RL, Dickson ER, Krom RAF. Hepatoportal arteriovenous fistula: morphologic features studied after orthotropic liver transplantation. Hum Pathol 1989;20:707-9.

8. Applbaum YN, Renner JW. Steel coil embolization of hepatoportal fistulae. Cardiovasc Intervent Radiol 1987;10:75-9.

9. Down NK, Makowka L, Langer B, Colapinto R, Wensel RH. Successful markedly elevated (gradient 33 $\mathrm{mmHg}$ ), which raised concern that irreversible changes in intrahepatic resistance might have occurred due to intimal fibroplasia of portal venulae over the 17-year interval that the fistula was clinically silent $(7,13)$. However, coil embolization of the fistula reduced the hepatic wedge pressure to $9 \mathrm{mmHg}$. This value is close to normal and represents evidence against hemodynamically significant portal sclerosis (13). On the other hand, one could speculate that the active hepatitis $\mathrm{C}$ that was noted two months before the first episode of variceal bleeding may have caused an increase in intrahepatic resistance and that this - in the setting of markedly increased portal flow due to the fistula - was sufficient to raise portal pressures to the point of inducing variceal hemorrhage.

treatment of a traumatic hepatic artery-portal vein arteriovenous fistula by interpositional mesocaval shunting. Can J Surg 1987;30:117-9.

10. Mallarini G, Saitta S, Cariati M, Nicorelli M, Caro GD. Embolization of AV intrahepatic fistulas. Eur J Radiol 1982;2:152-6.

11. Tegtmeyer CJ, Bezirdjlan DR, Ferguson WW, Hess CE.

Transcatheter embolic control of iatrogenic hematobilia. Cardivasc Intervent Radiol 1981;4:88-92.

12. Bedell JE, Keller FS, Rosch J. Iatrogenic intrahepatic arterial-portal fistula. Radiology 1984;151:79-80.

13. Donovan AJ, Reynolds TB, Mikkelsen WP, Peters RL. Systemic-portal arteriovenous fistulas: Pathological and hemodynamic observations in two patients. Surgery 1969;66:474-82. 


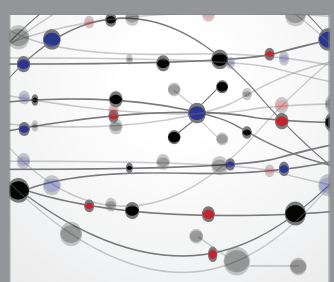

The Scientific World Journal
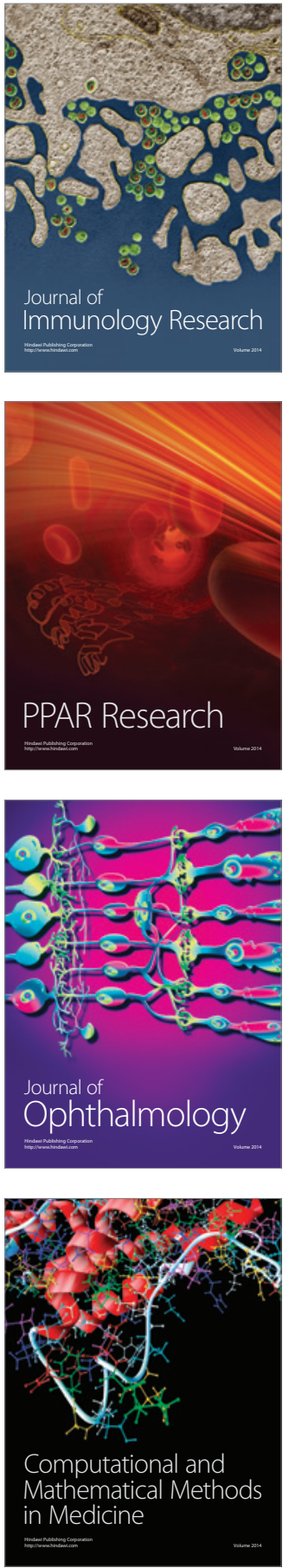

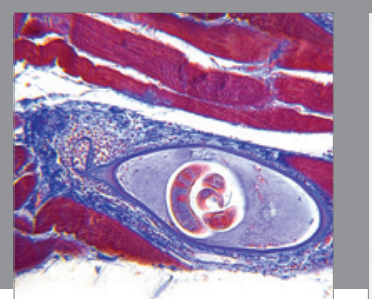

Gastroenterology Research and Practice

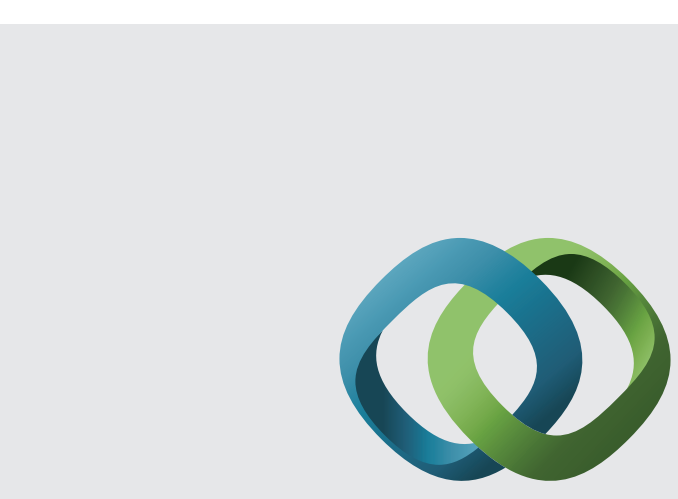

\section{Hindawi}

Submit your manuscripts at

http://www.hindawi.com
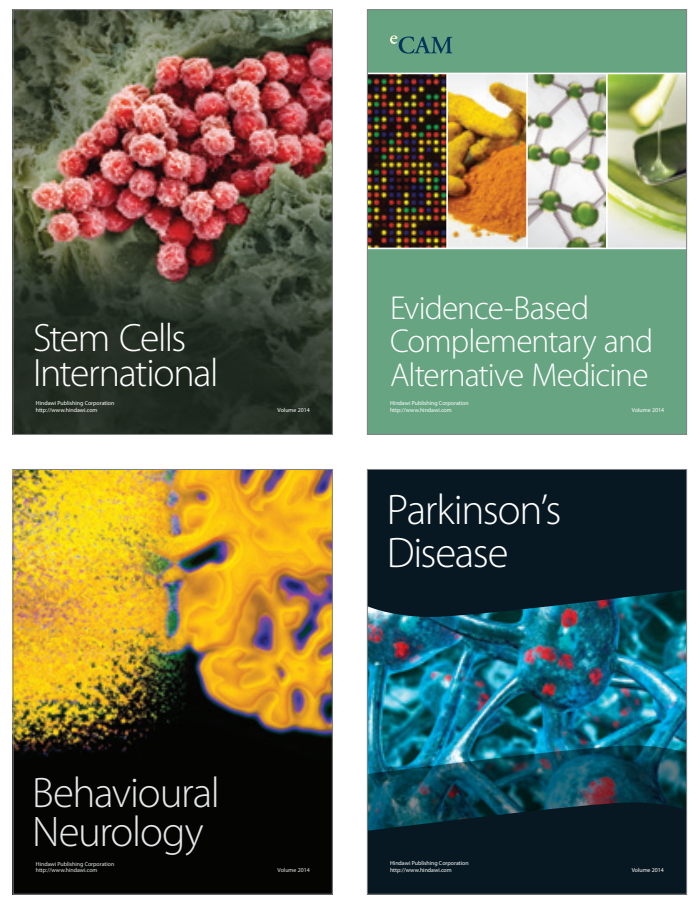
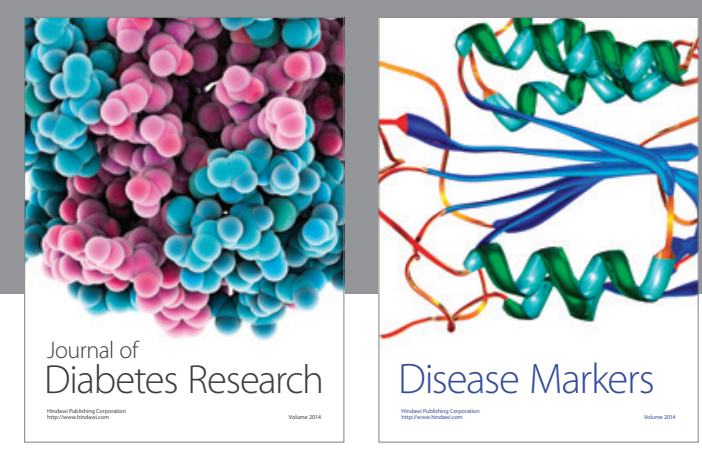

Disease Markers
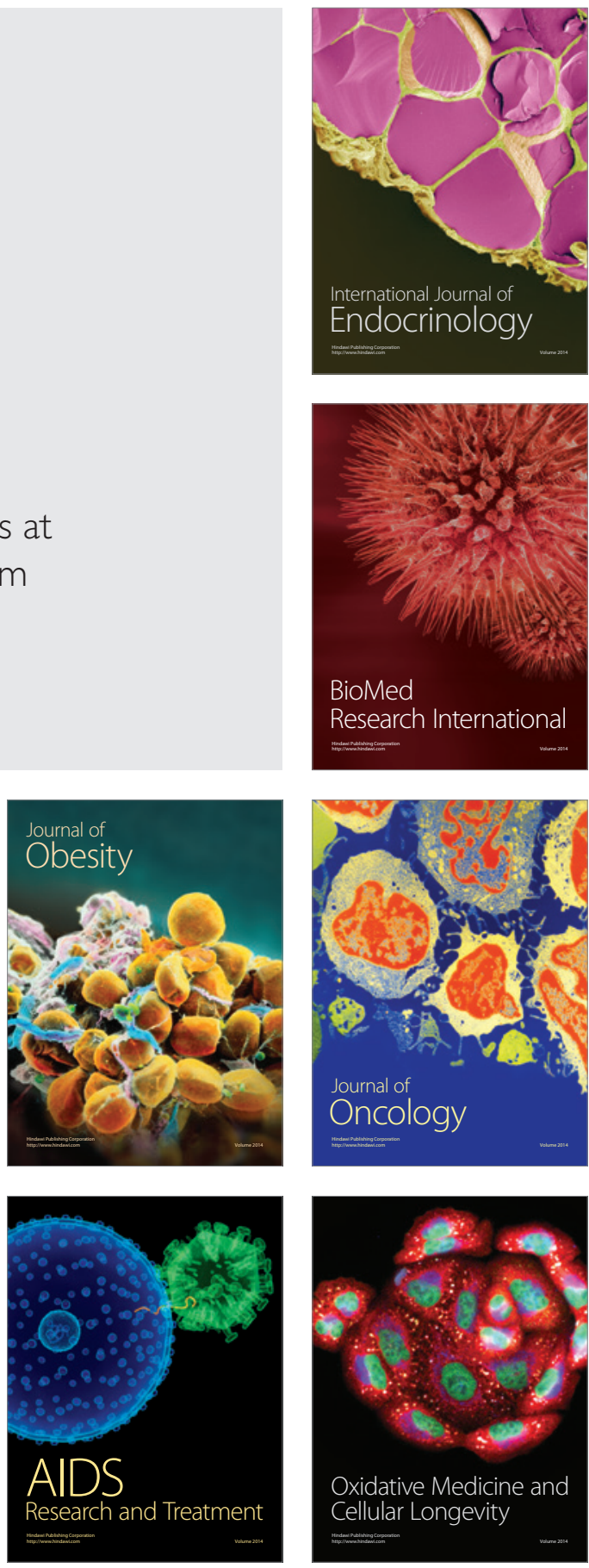